\title{
Thought in Culture
}

\author{
Merab K. Mamardashvili
}

\begin{abstract}
This essay on "Thought in Culture" was published twice in Russian, in 1989 and 1990, both versions being transcriptions of Mamardashvili's lectures delivered orally. This English translation, by the Dutch philosophical scholar, Evert van der Zweerde, is the first to be published. The question of thought is considered in the context of the question of suicide, albeit not in the sense Albert Camus spoke of it, but, in the sense of the old philosophers, as the existence of the primordial evil in human nature. This primordial evil is in Man's powerlessness (немогота), in that which is beyond Man's capacity. Through this dialectic of power and powerlessness, Mamardashvili explores the relationship of the structure and function of thought in culture.
\end{abstract}

\section{Keywords}

mirror-world [зазеркалье] - self-overcoming - human consciousness - analytical lack of content [несодержимость] - thought as performance

I would like to consider the topic of thought in culture, referring to a miracle of thought and to its impossibility, other than as a miracle, to take place in culture. In culture, there are, here and now and always, as if in an anti-world, some shades or images that do not cast shadows themselves and that live, in the words of François Villon, "without a life." As a matter of fact, when dealing with these images we have to pose ourselves the question about "how to get out of

* М. Мамардашвили, “Мысль в культуре," Философские науки, №. 11 (1989), pp. 75-81, and also Мераб Мамардашвили, Как я понимаю философию (Москва: Прогресс, 1990), pp. 143-154. Both versions are transcriptions of Mamardashvili's lectures delivered orally. Note of the translator, EvdZ. 
this fog?," especially when this fog has an epidemic character, the character of an unexpected and massive epidemic, which conceals, to my way of thinking, a kind of inner suicide. In many respects, therefore, the question of thought is at the same time also a search for an answer to the question of suicide, albeit not in the sense Albert Camus spoke of it, but, in the sense of the old philosophers,, as the existence of the primordial evil in human nature. This primordial evil is in Man's powerlessness (немогота), in that which is beyond Man's capacity. Man. This powerlessness (немогота) sits there, like an annoying splinter, which Man wants to get rid of as quickly as possible. But rather than do that, he is first eager to accuse the whole world of imperfection, not noticing that he is performing a suicidal act, first by destroying the world around him, and then by pulling himself out by the root. In other words, I want to say that precisely this root is unbearable.

It is this nagging splinter of the unbearable which evidently can be taken out only by an act of thinking.

One might ask: does not "high spirituality" come into it at all?

I think that the words "high spirituality" should be treated very delicately. In fact it might be located rather "low" - nobody knows this, just as nobody knows, where the body is located (I have in mind the Kantian approach to this problem). The sense of balance and harmony, all that is contained in the simplest human caprices, even, let us say, in laziness, only looks like an act of some kind of spirituality post factum, in retrospect. The whole trouble is that it is practically impossible to localize spirituality. The use of lofty concepts is the biggest temptation for Man, to which he easily succumbs, thinking that the mere fact of referring to them ennobles him. In reality, however, the problem is that concepts in general as such do not analytically contain in themselves the state of thought.

The state of thought is always an additional live act, occurring simultaneously with the meaning of concepts, including lofty ones. Once it has occurred, such a state is indistinguishable from the concept in which, alas, it is not contained. The living is visible only in its presence and we cannot grasp the difference between what is living what is dead in the concept.

What I am saying seems very important to me also because it allows us to draw closer to an understanding of what we are actually thinking about and what really worries us when we talk about culture. Historical experience shows that culture is not a set of lofty concepts or sublime values, if only because no values, no achievements, and no mechanisms can serve as a guarantee in this case. It is always possible to fall into the abyss from any heights of culture. 
Consequently, what I call the state of cultural, or, let's say, the state of thought (discourse), is a historical point, self-sustaining and staying alive on an insanely twisting curve. It does not leave lack of culture (бескультурье) behind. Culture is not something that arises out of chaos. Chaos and lack of culture are neither behind, nor ahead, or sideways, but surround each historical point. Just as in mathematics, rational numbers are surrounded by irrational numbers at every point. This is also due to the fact that the cultural form of existence of our thoughts (for nothing exists without form) essentially presupposes non- knowledge (незнание) as its ground. That is to say, some kind of vacuum that is left by the ontological structure of both the world and of thought in order to be filled with a live act, a living, tense, volitional state. For thought to be, there has to be the will that thought should be. This, by the way, is what is called pure thought. It is the case when the term "thought" is as it were redundant, because thought is not produced mechanically. I will try to explain what I mean (by analogy) through the example of faith.

We all know the following sayings, which usually make us laugh: "I believe because it is absurd [credo, quia absurdum]" or "I believe because it is impossible" (two versions). But Tertullian, who said this, knew perfectly well what the state of faith means. Indeed, how can we have faith in what is produced by some mechanism, independently of faith itself? Here, in addition to such a state, the term "faith" is simply redundant and, according to Occam's rule, must be treated as an aphorism. We can actually speak about faith only in the case we are dealing with something that cannot exist apart from the act of faith itself. Only that which is otherwise impossible or otherwise absurd can be an object of faith or through faith. The mystics have known this for a long time. They perfectly understood the essence of the matter, the essence of those acts of consciousness which are accomplished here, when they said that the actual object of faith is faith itself, that it is the renewal and rebirth of the very capability and force of faith. Another thing is that such acts are dissolved, already at the moment of their realization, into some content that is revealed to us based on those same acts, and we therefore do not notice the act itself in its pure form. For that, i.e. to grasp it, there is a special technique - the technique of religious and philosophical thinking.

So, returning to culture, its problem in fact is not how we can deal with those acts of human spirit and human know-how, existing and remembered by us, but how well we understand that all this is not self-sufficient and not selfconstituted, that the chaos, as I said before, is not behind, but surrounds each point of culture's existence inside culture itself. An additional, continuously self-fulfilling condition of culture is the - always accidental - occurrence of 
precisely those kinds of living states or living acts, which in themselves contain no value or use, but which are what Kant called "infinite values" or "purposefulness without a purpose" ["Zweckmässigkeit ohne Zweck" Ed.] After all, value is something by definition finite, whereas we are speaking about the "infiniteness of value," that is, about what never, not at any given moment, has a concrete, quantifiable value, but is rupture and displacement.

And so, if these acts do not occur, if there do not exist in a culture a sufficient number of people capable of maintaining this at the acme of there own effort, then nothing exists. And if there is something existing, it is just shadows that look like the living. I will refer to an example of the obscenity of human existence.

I have in mind the question of whether we should or should not drink wine. As is well known, there was a time when our movies and TV shows banned elementary human gestures, such as those by means of which a person raises a glass, clinks it, brings it to the mouth, and swallows. Consequently, it became possible to delete from Pushkin's text lines such as "и пунша пламень голубой ["the blue flame of punch"]" and "содвинем бокалы" ["let's raise our glasses"]. What is this, if not a foolish round dance of shadows? Tap your feet twice, clap your hands thrice. As if all people were obliged to participate in this foolish round dance.

Behind any such act of "necessity" there stands, of course, a concrete explanation. The reasons for inclusion in this round dance are always concrete and humanly understandable. As is it understandable, for example, that where there is the least understanding, the most widespread word - if you make a frequency dictionary of the language - is "you understand [понимаешь]": "you understand, don't you? [ты же понимаешь]," "of course I understand [конечно, я понимаю]," “we understand [мы понимаем]."

These concatenations of mutual winks, this mutual understanding secretly shared by all of us, is the logic of that kingdom of shadows in which life is impossible if we have any kind of sensitivity, not because we are cold or without shoes, but because we are first of all wounded in being. And when this foolish round dance is performed on the scale of a huge country which claims to be of global significance, and when, by means of this, the seemingly invisible, but in reality highly perceptible wounds to our being, are piling up, then what can that end with? What are people who can follow such allegedly human laws capable of? In his day, Nietzsche, possessing an amazingly sharp sensitivity, not accidentally of course called such people "the last men." Usually, when people speak about Nietzsche, they recall his "Übermensch," but the latter does not stand alone in Nietzsche's symbol. It is, as it were, a three-step symbol. There is Übermensch, who is not some sort of real being or a special 
breed of people, superior to others, but who is a kind of limit-state for Man: Man can only become Man by trying to reach this state. The second member of the formula is that being which can only be Man when he transcends himself in the direction of Übermensch. All existing, as someone said, must exceed itself in order to become itself.

The third member of the formula is "the last Man," that is, precisely he who does not accomplish the act of transcending himself. The last Man is described as follows: "These are people who even do not know how to know what a star is and who cannot despise themselves. They just repeat: 'We are happy, we are happy' - and they wink." This is a literal quotation from Nietzsche.

From here, it seems to me, can be deduced a great number of cultural realities and actually the whole problematic of "culturology" [культурология] ${ }^{1}$ and, most importantly, the reasons for our interest in it. Not our interest in problems of culture, but of Man in culture. We are talking in this case about some hidden preconditions of the development and existence of culture. And that, which I have partially described as a world of shadows, has, of course, the most direct relation to these preconditions: to that real catastrophe which all of us experience and which is more terrible than all the other disasters. I refer to the anthropological catastrophe, that is, the degeneration, by some consecutive series of transformations, of human consciousness in the direction of an antiworld of shades or images, which in their turn do not cast shadows themselves, the degeneration into some kind of mirror-world [зазеркалье], ${ }^{2}$ made up of imitations of life. Historical Man of course cannot recognize himself in this Man who is an imitation of himself.

Moreover, real culture is not to be found in museums and cannot be reduced to the number of visits to those museums. It consists in the feeling of being or non-being, which I have tried to describe.

So, all this has a fundamental relevance to thought, to the possibility of our accomplishing the act of thought.

Inasmuch as this is not about issues in culture, but about metaphysics and ontology, I would put it this way: cultures are immortal. Death never makes its appearance in the plane of any culture. The field of any culture is infinite. It is

1 It can be surmised that in all probability Mamardaashvili was quite critical of the culturology that mushroomed when he wrote this piece (1989) - it certainly is not a neutral description of "cultural studies" but points to the sudden emergence of those cultural studies as a cultural phenomenon it its own right. Note of the translator, EvdZ.

2 The dictionary does not give a good equivalent for "zazerkal'e," but it is where Alice ended up on the other side of the looking glass. Note by the translator, EvdZ. 
similar to what Wittgenstein in his day said about the eye: "the field of the eye is infinite." Whatever we see at whatever distance - the eye will see it; the eye sees what it sees. In culture it is the same. Culture is infinite. However, this kind of infinity, naturally, contains an element of bad infinity, too. And, what is more, falling out of infinity by embracing thought, is necessarily connected with the appearance of the symbol of death, because we can only arrive at thought by changing ourselves, by having stopped being what we were before. Consequently, the ontological structure of being constitutes itself only by the trigger of our effort, when, first, we become different from what we were until then, and, second, we get there by our uninterrupted continuation of ourselves. Here, there is a vertical that is cutting the cultural planes. And on this vertical there is a symbolism that is never given in the planes themselves.

Every culture is immortal. The vertical cross-section alone can inject into it that new state - the known or contemplated symbol of death - as a state after which being opens itself up and we can find ourselves in a state of thought. We cannot do this through the exercise or the mere continuation of our readily available logical and cultural resources. That is why I am coming back to that spirituality about which I spoke in the beginning, to the transformed states, in which reality is constituted in its totality, one that is always different from our concepts and from the logical possibilities projected from them.

Obviously, there is some force acting acts in the world, which is bigger thanus, producing in us some kinds of states - there where we have renounced ourselves - in order that we may be worthy of that which can happen to us.

In other words, to understand, to see what actually is, is only possible in determinate limit states. I recall the great Kantian idea, which is often misunderstood.

What Kant said about the limits of cognition is usually understood as there being certain boundaries, beyond which Man cannot go: the boundaries of our mind, action, and so on. However, the fact that such boundaries exist is obvious, and it was not the problem Kant was trying to address. It is not about the boundaries of the human mind and of human capabilities. The Kantian problem was the problem of limit states, that is, those states that, in principle, only exist on the borders. It is the problem of the fields and tensions caused by the existence of those very borders. For example, pure will [чистая воля] is a border representation or a border state, never a part of the world that is outlined by the border, even though it is by virtue of this that something can happen in the world itself. Or, say, an ideal is a border state. What I mean is not that it is unreal because there is no just or ideal society in the world, which would be a real fact on which we would be able to orient ourselves and which we could approach. In his day, Engels created the, in my opinion rather unsuccessful, 
metaphor, borrowed from everyday discourse, of the asymptote, that is, of some approximation of absolute truth by way of the addition of relative, cumulative truths. Now this is impossible due to the nature of the concepts themselves and to the way human aspirations are shaped in the first place. For there to be something in the world, worthy of being called beautiful, just, etc., there have to exist the aforementioned acknowledged states. Inside the world there are no similarities or approximations; any state is equally limited and equally distant from infinity.

There is no such thing as greater or lesser perfection. The sublime is always equal to any other sublime. ${ }^{3}$ That is how the world is shaped. Unfortunately, our brains are shaped differently. Departing from how they are shaped in the sense of our everyday perceptions, we cannot proceed to thought through the continuum of our forces, of our physical and object-related apperception. In order to achieve that, I repeat, we have to refrain from projecting our (previous) selves into the next moment of time.

Consequently, the problem of culture (that particular culture which is more successful than others) is the following: is change in the world possible. Can we be only such as we are, or are changes possible in the world, in particular, the self-overcoming of Man? For this is essentially this the mission of European culture. Therefore, in many respects our question is not just about culture or about the realities of cultural history, but about our real spiritual needs or about "Man in culture". The answer to this question cannot be final or completed, if only because we address it to ourselves. But what I want to say is that when we ask this question, we are questioning ourselves about our own origins, that is, we are looking to reunite with our spiritual homeland, namely the European Christian cultural tradition. I use the word "Christian" not in the confessional sense, but I refer to our capacity for change. What is more: when an individual comes to the limit of endurance, there is already at work some primary concept of difference, some kind of spark which is an indication of some inner primal image, given to the individual which orients him towards that image, bypassing all external authorities, injunctions, or an ideal hierarchy. It is a simple orientation or pathway. It is enough to enter this pathway, and something will eventually come to our assistance. The most important thing is to be worthy of it, no matter what happens. This is the foundation or basis of the culture of Modernity. The one-on-one existence of Man and the world, without any guarantees which would be external to the person and to human consciousness, just an open space in which a path is only outlined, the

3 "Sublime" here seems close to the Kantian position, but the Russian original also translates as "superb." Note by the translator, EvdZ. 
path that you must make for yourself. This definition, by the way, coincides with the definition of "enlightenment."

As we know, Enlightenment is a purely negative concept, that is, a concept which does not designate some totality of positive knowledge that could be spread amongst people and handed onto them. Enlightenment, in Kant's words, is the adult state of mankind, in which people are able to think with their own mind and to act upon it, without the need for external authorities and being lead on a string.

Thus the question arises: are we enlightened?

And a second question is: what are we looking for when we speak of culture, why do we speak about it? Obviously, when we speak of culture, we return to the original meaning of Enlightenment as the foundation of Modernity: to such of its characteristics as the active engagement of the individual, the individual's rights, the public expression of individual thoughts, etc. The second premise which is also important here is the distinction between physically observable existence and what philosophers call existence. That is, actualized existence, covered by verbs such as "to be there" [пребыть], "to enter historical existence," which is obviously different from intention. Just as, say, the intention of a debt is distinct from the debt itself, the intention of thought is distinct from thought itself, the intention of sincerity is distinct from sincerity itself, and the intention of honour is different from honour itself. In the tangible dimension, we cannot distinguish, for example, honour from the intention of honour (the more so since in its bearer, the intention is expressed in the mental content of concepts and ideas). An act is the state of thought which has taken place. ${ }^{6}$ And once it has occurred, it is irreversible. As Kant would say in this case: "The pure will has determined itself." And this does not depend on the consequences, the success or failure of the act itself. The reference to its "purity" still says nothing about the determination of the will, once it has

4 The term "enlightenment" should normally be written with a capital E. Clearly, Mamardashvili, like Kant, refers to The Enlightenment, but at the same time what he is talking about here is not limited to that, or to any historical period. Note of the translator, EvdZ.

5 Mamardashvili here uses the very unusual but grammatically possible form of the perfective aspect of the standard verb пребывать - to abide/stay/be in a place or in a state. It appears to be an allusion to Heidegger's term "dasein" in its various grammatical permutations (as noun, adjectival phrase and verbal expression "da sein"). Note of the translator and editor. EvdZ.

6 It could be added here that C S Peirce claimed that "thought is essentially an action": "Thoughts are events, acts of mind." Compare C S Peirce, Peirce on Signs: Writings on Semiotic by Charles Sanders Peirce. Ed. James Hooper. (Chapel Hill and London: The University of North Carolina Press, 1991), pg. 166 and pg. 69. Note by the translator EvdZ and editor SV-G. 
occurred. Just as, by the way, the reference to a case of injustice in the functioning of a legal system does not characterize the legal system itself. Why not? Because the purpose of law is law. The purpose of law is not this or that instance of the establishment of legality, but law itself. Just as the purpose and object of faith is faith itself, or the purpose and object of thought is thought.

For example, we all know about the illegal realization of intentionally legitimate purposes, when truth or social justice is established by means of violence. That is a violation of the basic ontic and ontological structure of the world, in which laws are achieved only by laws, rather than by intentions, no matter how lofty those intentions are. The same can be said with respect to freedom. Sometimes people say: "Show me a true court, genuine justice." And when it is not found, they usually respond: "America or Russia - it's everywhere the same thing. People tell lies everywhere." Evidently, since the ontic structure of the world is such that freedom produces only freedom. And nothing else. It is impossible to show freedom as an object or, even less, to put it in your pocket.

For the solution of these sorts of problems there exist forms. Law is a form and only a form. And it stays alive until we try to distribute its content among people in some fair manner; form is only the chance to achieve that about which it speaks. Hence, it is the form of the legal order [правопорядок].

Art is a form. Science is a form. Philosophy is a form. A form of what?

I will conditionally call these cogitative devices "time machines" or "thought machines." Why time? Well, naturally, if we spoke about the vertical that is cutting the cultural planes, then the points on this vertical, in relation to each of the cultural planes that are located in the projection of infinity, will be a standing still of time [стояние времени], which is given to us in the form of a moment, and a moment can be a complete eternity. Its dimensions do not coincide with our distinction of past, present and future. I will return to these distinctions which I have already used in the course of my exposition.

So, I have said that we employ the term "thought" in at least two meanings; it is inevitably dual. On the one hand, it indicates the intention of thought or, let us say, the pre-intention of a state of thought that belongs to the signsubject domain, and on the other hand - it is some kind of living state of thought. In the first case, it is a matter of the logical possibilities of thought. The intention of thought is its logical possibilities. The second is the presence of living thought, conceptually indistinguishable from the first. Or its potentiality in contrast to its possibility. Potentiality in contrast to possibility is the possibility that at the same time possesses the power for its realization. Thought realizing itself as live. But we call both of them thought. Although in the second sense (the state of thought), it is not analytically included in the content of the concept that designates the same thing. For example, the state 
of goodness is not analytically included in the concept of the good. Once it has occurred, it merges with the concept, but it is impossible to obtain an appreciation of a concrete act in terms of goodness through application of the concept of goodness. That is impossible.

I call to mind, in this connection, yet another Kantian formula, which sounds a little bit different. When Kant, all the time rotating with his thought along different orbits and again returning to a single point, says that "it is impossible to learn from ideas by means of ideas," or when he says that reason ${ }^{7}$ disposes over "only probability," he means the same thing as what I have called the analytical lack of content [несодержимость]: that a certain fact of reason is not analytically contained in the concept of reason.

The actual side is the side of life, i.e., the live power of possibility, ${ }^{8}$ and not merely logical possibility or intention. But in both cases we speak about thoughts and we use the term "thought."

And the second point which played a role in my account: thought refers only to what exists in the moment of and within thought. It's as it were the moment of living movement. In an instant.

Let's take a simple thing. There is a notation of a musical sound. But I claim that the sound exists only when it is being performed. All cultural phenomena are like that: a book is read and it exists only when it is being read. It does not have another existence. A symphony exists only when it is being performed. A landscape exists when it is being looked at through the eyes of the presently visible picture, since nature itself is not a landscape. Nature is a heap of stones, an abundance of grasses, water and trees.

The same applies to society. Human living together is not yet a society.

Society is what exists at the moment of the performing of human know-how, of a form by means of which social events occur. Only thanks to them does society exist. But these events may or may not be accomplished. Just like words that can be mere signs, without flesh and blood, in which case we are dealing with doublets/counterfeits [дублями]. First we die in the letter, in the sign, and then we start to "live" or to imitate life. I will give an example or, rather, two examples.

Such a quasi-existence, or, as I already said, an existence beyond the mirror, in which we cannot accomplish the act of thought, is connected to the fact that the internal sources of thought themselves have been damaged, not because of

7 Mamardashvili's use of разум points to the emphatic Kantian notion of Vernunft (as opposed to Verstand = рассудок); to Mamardashvili, this opposition of Vernunft and Verstand is obvious, but in English it is not so easily rendered: reason vs. intellect is what comes closest. Note by the translator, EvdZ.

8 This "live power of possibility" is what was called "potentiality" above. Note by the Translator, EvdZ. 
some prohibitions of censorship, but simply because everything has as it were already been performed. Any movement of the soul, happening just now, is already outlined (designated), and we focus only on the sign of a sign or on the appearance of an appearance. It is from here, apparently (because this kind of regression is always inevitable), that there occurs - I am now moving on to the example - in our culture a revival of the cult of the dead, including the interest for and popularity of the ideas of Nikolai Fyodorov who once called upon the living to engage in the resurrection of the dead. It is striking, that even in the twentieth century the Russian intelligentsia, being a people's intelligentsia, is not carrying out its intellectual responsibility in the sense of preserving the dignity of thought.

Not so long ago I found in a newspaper a description of how the Pioneers ${ }^{9}$ discovered the remains of warriors who died in the war. The article was placed in the context of a discussion of the topics of commemoration and of paying tribute to the fallen. So, the way of presenting the material - both the state of the person who described it and what was described - shocked me personally a lot.

Moreover, to complete this example, I add that I had this feeling for quite a while. I did not know that detail, but it is so expressive that it speaks for itself. Very often, after all, the truth is pronounced involuntarily. It is not on our minds and suddenly it is in front of us. I am talking about documentaries of Lenin's funeral, where I was shocked by a poster. It was not the poster itself that shook me, but a coincidence, a direct expression of what I thought on this occasion. The poster said, in big letters: "Lenin's tomb is the cradle of humanity." Here we have an expression of what worries me: life after death. Life imitating life. And with this is related what I would call linguistic acceleration, but in the opposite direction, when we begin to live after death. Like Gogol's hero Bashmachkin, whose spiritual life was in fact clearly provoked by a dead letter, devoid of any meaning. The lyrical game started after the death of the letter. A letter, a word is usually the acme of the life of the spirit, but here everything is the other way around, though also its own poetry, its own humanity, a special logic, and including the reverse acceleration. Having first died, i.e., not having brought to fruition what presented itself to us at the appropriate moment, having missed our moment of development - we are rushing towards ultimate regression at high speed. It is well-known that there are things that, if they did not happen with a child within the first five years, they will never happen. In subsequent years, it cannot be compensated by anything. A kind of Leibnizian petition that cannot be compensated by any, not even by the most powerful

9 Mamardashvili is referring to the "Soviet scouts," a communist youth movement. Note by the translator, EvdZ. 
intellect, if it did not exist or happen in the first place. Those things have a marker of time - "now." At some point it didn't happen, and that's it.

I think that in the history of Russia, too, many things have not happened at their proper moment - and have turned out to be dead. As a result, Europe flourished before our eyes and yielded its own fruits, including negative ones. But we headed for some post-European state, not having experienced any contemporary European or even pre-European states, missing the appropriate hour. And actually the speed of construction of our future society turned out to be monstrous and dictated rather by the linguistic obsoleteness of what we did not live through or experience ourselves. Because our discourse is a European one. Nikolai Chernyshevsky and others spoke in a European discourse, but for them capitalism, bourgeoisie, civil society, all those were stages already passed that could be by-passed. In reality, however, the speed of socialist transformations was determined by the speed of the race for what had been missed. A monstrous speed, but with a reverse meaning. That was carried out precisely by thought. I am describing thought that has not executed the laws of thought. But the laws of thought are executed only by well-adjusted "machines" - "time machines."

Finally, the last example. Everything that is visual and objective appears in another form, is duplicated. Take theater for example. When we go to see a performance - I take the ideal case - we already know the text in advance. Everything is known. Why do we need theater then? What is happening? What happens is that in the theater we relate to something we cannot possess, and that cannot be understood in any other way. Theater is the "machine" that introduces us into that state, which exists only when it is performed. It would seem that it is written in the text, we only have to read it, but the understanding, if it happens, can only happen in the theater.

You understood, a change took place in you, a catharsis took place but the words went away, because an organized strong form was operating.

Science is like that, too. It is all "machines," built in such a way that they can beget in us something we cannot receive in a natural way, something at which we would never arrive by a simple extension of ourselves, an extension of our available natural mental and physical powers.

And such machines require, of course, a societal, public space. Since when that disappears, thought disappears, too. Public space is precisely the condition of thought itself. It does not exist in order to irritate or upset someone, or to make him happy. Thought exists only in performance, only in a space that is not occupied by any prejudices, taboos, etc.

These are the internal conditions of thought, because, first, it does not exist in the head of an individual but is spatial; otherwise it cannot articulate itself. 
Therefore, in this sense, too, there cannot be such a thing as secret knowledge knowledge about ourselves, as if we had been deprived of external space, but inside ourselves we would be very clever and understand everything. In fact we do not understand, due to the laws of thought itself.

Aleksand Blok said that the destruction of external space is the destruction of the inner sources of harmony. He suspected such a possibility. This means that it is not when the products of harmony are distorted or persecuted, but when the inner sources, the internal possibilities of thought are destroyed, that thought itself is destroyed, because there is a law: Man is not wholly in Man. We come to ourselves from afar. From very far. And, by the way, during that time (and in space), as long as we are approaching ourselves, many things can happen - we can also fail to reach ourselves, due to the speed of which I spoke.

Second and consequently, we can say that all thinking is not enough for thought, not even for a single accidental thought. What is further needed are those things that I have called additional or living acts, living states that have their own ontological and ontic conditions of possibility. Those conditions can be destroyed. And then it is not enough to just will memory, because it is possible to know what one needs to remember; that is not where the problem lies. It is constantly being said now that it is necessary to remember, that there should be memory, tradition, etc. All this is absurd from the perspective of proper thinking, in the context of the conditions of possibility of something being in the first place.

I repeat that there is a difference between the intention of thought and thought itself, or between the intention of remembrance and memory itself. The point is not that it is possible to want to remember, but that wanting to remember is not yet memory. As Maksimilian Voloshin once said:

And in delirium he cannot forget himself,

And from sleep he cannot wake up.

To fall asleep in delirium, when it is impossible to forget oneself and impossible to wake up. This in-between state obviously is our state, too, if we do not have our "time machines."

\section{Translated by}

Evert van der Zweerde

Radboud University, Centre for Ethics / Soeterbeeck Programme,

Faculty of Philosophy, Theology and Religious Studies,

Nijmegen, Netherlands

evdzweerde@phil.ru.nl 